\title{
O corpo como função de suplência imaginária em um caso de psicose ordinária
}

\section{The body as imaginary supplement function in a case of ordinary psychosis}

\section{El cuerpo como función de suplencia imaginaria en un caso de psicosis ordinária}

\author{
Tiago Humberto Rodrigues Rocha* \\ Universidade Federal do Triângulo Mineiro - UFTM, Uberaba, Minas Gerais, Brasil
}

\begin{abstract}
RESUMO
O presente trabalho é fruto de uma pesquisa de doutorado para obtenção de dupla titulação realizada entre o Brasil e a França. O estudo foi conduzido a partir de entrevistas semiestruturadas realizadas com homens que haviam se submetido a intervenções médicas, com finalidade estética. Os entrevistados foram encaminhados pelos próprios médicos que realizaram as intervenções após consentimento dos participantes. Durante a realização das entrevistas foi encontrado um sujeito fazendo uso bastante particular de seu corpo. Tal uso suscitou a possibilidade de se tratar de um caso de psicose ordinária, estabilizada a partir da introdução de um termo com função de suplência imaginária à foraclusão do Nome-do-Pai. Assim, este artigo traz a análise dos relatos de um jovem homossexual de vinte e sete anos que realizou uma série de intervenções estéticas no corpo. Do sentimento de estranhamento pelo não reconhecimento da própria imagem no período pregresso à cirurgia de maior impacto - uma prótese peitoral masculina - até a assunção de um corpo - cuja função é de suplência imaginária à foraclusão do Nome-do-Pai - o jovem pôde estabilizar-se a partir da organização de uma tripla externalidade reconhecidamente em desordem: social, corporal e subjetiva. Ao final do trabalho reconhece-se a necessidade de novas investigações em torno dos possíveis efeitos clínicos e metapsicológicos decorrentes dos intensos processos de identificações necessários para sua estabilização.
\end{abstract}

Palavras-chave: corpo, psicose ordinária, suplência imaginária.

\section{ABSTRACT}

The present work is the result of a double degree doctorate research carried out among Brazil and France. The study was conducted from semistructured interviews with men that were submitted to medical interventions with aesthetic purpose. The interviewees were referred by the doctors who performed the interventions after consent of the participants During the accomplishment of the interviews it was detected a subject making a very particular use of his body. Such kind of use has raised the possibility of dealing with a case of ordinary psychosis, stabilized by the introduction of a term with an imaginary supplement function to the foreclosure of the Name- 
of-the-Father. Hence, this article considers the analysis of the reports of a young homosexual of twenty-seven years old who performed a series of aesthetic interventions in his body. From the feeling of estrangement, due to the non-recognition of the image itself in the period prior to the surgery with greater impact, - a male pectoral prosthesis - until the assumption of a body image - whose function is to do imaginary supplement to the foreclosure of the Name-of-the-Father - he was able to stabilize his psychic condition from the organization of a triple externality in disorder: social, corporal and subjective. At the end, the need for further research is recognized in view of the possible clinical and metapsychological effects due to the intense identification processes required for its stabilization.

Keywords: body, ordinay psichosis, imaginary supplement.

\section{RESUMEN}

El presente trabajo es fruto de una investigación de doctorado con doble titulación realizada entre Brasil y Francia. El estudio fue conducido a partir de entrevistas semiestructuradas realizadas con hombres que se habían sometido a intervenciones médicas, con finalidad estética. Los entrevistados fueron encaminados por los propios médicos que realizaron las intervenciones después del consentimiento de los participantes. Durante la realización de las entrevistas fue encontrado un sujeto haciendo un uso bastante particular de su propio cuerpo. Tal uso, suscitó la posibilidad de tratarse de un caso de psicosis ordinaria, estabilizada a partir de la introducción de un término con función de suplencia imaginaria a la "forclusión del Nombre-del-Padre". Así, este artículo trae el análisis de los relatos de un joven homosexual de veintisiete años que realizó una serie de intervenciones quirúrgicas estéticas en su cuerpo. De la sensación de extrañamiento por el no reconocimiento de la propia imagen en el período preparatorio a la cirugía de mayor impacto - una prótesis pectoral masculinahasta la asunción de un cuerpo - cuya función es de suplencia imaginaria a la forclusión del Nombre-del-Padre- el joven puede estabilizarse a partir de la organización de una triple externalidad reconocidamente en desorden: social, corporal y subjetiva. Al final del trabajo, se reconoce la necesidad de nuevas investigaciones en torno a los posibles efectos clínicos y metapsicológicos derivados de los intensos procesos de identificaciones necesarias para su estabilización.

Palabras clave: cuerpo, psicosis ordinaria, suplencia imaginaria.

O presente artigo apresenta o resultado de uma pesquisa de doutorado para dupla titulação entre o Brasil e a França. Em seu princípio, a pesquisa visou investigar os possíveis efeitos subjetivos das práticas de cuidado estético em homens na contemporaneidade. Após as realizações das entrevistas não foram apontados índices significativos de possível mal-estar entre a assunção de um modelo de masculinidade relacionado a práticas de cuidado estético. Contudo, foi encontrado um caso bastante particular do uso do corpo por um jovem homossexual cuja hipótese diagnóstica é de se tratar de uma estrutura psicótica estabilizada de maneira ordinária.

Acredita-se que as modificações realizadas pelo jovem lhe servem como uma forma de suplência imaginária à foraclusão do Nome-doPai, tal como será detalhado. Este arranjo singular parece estar em 
consonância com as expectativas do Outro social que o circunda, uma vez que o laço (pseudolaço) social estabelecido é sustentado e constituído a partir das práticas estéticas realizadas em seu corpo, com especial atenção a um implante peitoral masculino. As práticas Ihe permitem um lugar de reconhecimento pela articulação de uma tripla externalidade previamente em desordem: social, corporal e subjetiva.

\section{Sobre a Psicose Ordinária}

Antes de passarmos à apresentação e à análise mais detida sobre o caso, cabe estabelecermos uma breve reflexão sobre o lugar da psicose ordinária no campo da psicanálise. O termo psicose ordinária foi utilizado pela primeira vez por Jacques Allain-Miller em decorrência de discussões clínicas que ocorreram entre os anos de 1996 a 1998. Diante do aparecimento de casos de difícil delineamento conceitual, o termo "inclassificável" ganhou certo gosto na comunidade psicanalítica da época. Empenhados em definir melhor este termo, foram propostas três conversações entre os analistas da época, cujas discussões clínicas trouxeram alguma novidade às categorias teórico-clínicas clássicas. Somente na ocasião da terceira conversação, a Convenção de Antibes, é que o termo se tornou estabelecido pela primeira vez, não sem deixar de provocar certo mal-estar em torno de seu uso dentro do campo psicanalítico ainda hoje. Assim, a partir da Convenção, ampliou-se as possibilidades de classificação para diferentes manifestações psicóticas: psicose compensada, psicose não desencadeada, psicose suplementada, psicose medicada, psicose em análise, psicose em terapia, psicose que evoluciona e psicose sinthomatizada - como a de Joyce (Miller, 1998).

Toda a discussão em torno da categoria ordinária para possíveis casos de psicose ocorreu em razão da dúvida constantemente presente entre vários clínicos sobre o que poderia desencadear uma psicose. Tal dúvida concernia aos casos de manifestações psicóticas que não se apresentavam sob a forma dos fenômenos elementares (delírios desencadeados e automatismo mental) e distúrbios da linguagem, classicamente necessários à primeira clínica de Lacan. $\mathrm{Na}$ prática, tratava-se da dúvida recorrente sobre o porquê de vários sujeitos passarem a vida sem manifestações tipicamente psicóticas e, ao mesmo tempo, apresentarem narrativas que deveriam incluir o desencadeamento de uma psicose. Miller (1998) enfatiza que a psicose ordinária não é uma categoria de Lacan, mas sim uma categoria clínica lacaniana que pode ser formulada a partir de seu último ensino, o que fomenta ainda mais mal-estar entre psicanalistas, em especial ao que toca o particular de cada Escola. 
Posto isto, quais seriam os sinais que caracterizariam uma psicose ordinária? Longe da pretensão de encerrar qualquer categorização, iremos trabalhar com a ideia de que a psicose ordinária possui a mesma estrutura clínica da psicose, e que sua distinção ocorre apenas no âmbito da própria clínica pelo modo discreto de suas manifestações e pelos modos singulares de estabilização, em acordo com a proposta de Maleval (2003). E mais evidentemente na psicose ordinária serão os "índices de não extração do objeto a, falhas discretas da capitonagem, problemas de identidade e prevalência das identificações imaginárias" (Avdelidi, 2016, p. 243 [tradução livre]). Estes índices colocam em evidência uma questão crucial ao tratamento clínico: a convergência entre a aparição do sintoma e o gozo real.

Não teríamos dúvida que os mecanismos imaginários que dão a sintomatologia não funcionam de maneira autônoma: eles são articulados à economia de gozo. Nestas formas mais elaboradas deste processo de estabilização, as identificações imaginárias aparecem em conexão com o real (Maleval, 2003, p. 54 [tradução livre]).

Ou seja, há uma conexão do sintoma e da identificação imaginária do corpo pulsional atravessado pelo significante, submetido à linguagem. Trata-se de um índice de relativa importância já que há sujeitos em que o sintoma pode conduzi-los à uma significativa adaptação social, uma vez que é possível responder às injunções de gozo advindas do Outro a partir do campo social. A discussão em torno da diagnóstica da psicose ordinária é sustentada por autores como Tironi (2010), por considerar sobremaneira o enfraquecimento das tradicionais formas de classificação na atual conjuntura de perda de referência de Um operador universal.

O que se torna evidente é que as transformações sociais acarretam também mudanças nos arranjos subjetivos que possam ocorrer em cada estrutura. Lacan (1998/1960) não titubeou em pensar as determinações sociais sobre a estrutura do sujeito ao afirmar que o Édipo sofre modificações conforme o sentido trágico que cada momento social pode conferir ao mito. Dizer que na Europa vitoriana de Freud os ideais funcionassem como elementos moderadores de determinados modos de gozo não faz do tempo atual uma espécie de "registro melancólico" de um passado áureo e perdido. Pelo contrário, a marca do tempo atual - e com isso o conceito de psicose ordinária parece ganhar força - é da passagem da clínica da interdição, marcada pela castração do desejo, para uma clínica que promove a função do mais-de-gozar, uma vez que fica cada vez mais evidente a presença do objeto a. Ao que Tironi (2010) afirma certa debilidade dos ideais, antes tradicionais, que balizavam o gozo. Segundo a 
autora, observa-se uma multiplicação de ideais que se colocam de modo distintos, tendo comoefeito identificações que se mostram quase que invariavelmente - débeis. O conceito de psicose ordinária parece ganhar maior reverberação no momento mesmo de passar à leitura sobre o alcance estrutural com o conceito de psicose ordinária. Para melhor compreensão do caso que aqui será apresentado, neste momento é constatada a necessidade de lançar mão de alguma teorização em torno do conceito indissociável ao avivar a hipótese diagnóstica de psicose ordinária: a suplência imaginária.

\section{Uma Breve Noção de Suplência I maginária}

Para melhor tratar o conceito de suplência imaginária convém realizar um rápido retorno à clínica psicopatológica clássica onde, desde Clérambault, a foraclusão do Nome-do-Pai (P0) tem como desdobramento a aparição dos, assim denominados, fenômenos elementares. Estes, anteriormente ligados exclusivamente aos distúrbios de linguagem e à atividade delirante, ganham certo alargamento conceitual na atualidade, tal como afirmam Maleval (2003) e Avdelini (2016), sendo classificados como:

a) fenômenos chamados de "automatismo mental"- conceito de Clérambault que permite agrupar na sintomatologia do paciente tudo o que é vivido como proveniente do exterior: pensamentos, ordens e vozes vividos como alheios, impostos de fora e que decidem a conduta do sujeito; b) fenômenos que concernem ao corpo, tais como experiência de decomposição corporal, de despedaçamento, de estranheza em relação ao próprio corpo; c) relatos de experiências inefáveis, a saber, vivências místicas de certeza absoluta, de comunhão com o todo (Zebrun, 2010, p. 4).

Tais fenômenos estariam presentes no momento denominado prépsicose, período que antecede o desencadeamento. A observação dos fenômenos elementares, desde a clínica de Clérambault até os dias atuais, trata de um efeito da foraclusão (P0) do Nome-do-Pai. Esta implica a impossibilidade de que a significação fálica $(\Phi 0)$ ocorra, o que não quer dizer a ausência por completo dos significantes. O que ocorre, diferentemente da neurose, é que com a foraclusão do Nomedo-Pai, a função paterna que poderia amarrar a significação dos significantes primordiais ao elemento fálico fica desaparecida (Lacan, 1998/1958). A zerificação da significação fálica (Ф0) está ligada a problemas de significação e não da ordem do significante. É isto o que Miller (1998) recupera como índice diferencial referente à psicose 
ordinária, separando-a da assim chamada verdadeira psicose e colocando os fenômenos elementares desaparecidos por detrás do arranjo que o psicótico pôde fazer antes que tais elementos viessem a ser percebidos. Lacan (1957) já havia tratado da distinção dos fenômenos ligados à foraclusão do Nome-do-Pai (P0) dos fenômenos ligados à zerificação da significação fálica $(\Phi 0)$. O avanço proposto por Miller será considerar a condição ordinária de vida na qual o psicótico pode mergulhar sem que seja percebido como tal. Diferentemente dos transtornos de linguagem - percebidos na paranoia sob a forma de alucinações verbais e imposição do pensamento - ou ainda do esfacelamento do corpo - como na esquizofrenia - a tese que Miller defende é que nos casos da psicose ordinária os fenômenos elementares estejam aparentemente ausentes devido à suplência imaginária realizada por um determinado significante à foraclusão do Nome-do-Pai. Para Maleval (2003), nos casos em que o delírio se apresenta de maneira mais elaborada, como na paranoia, por exemplo, ele mesmo serve como suplência imaginária à suplência faltosa do Nome-do-Pai.

A temática sobre os mecanismos de suplência e compensação imaginária estão presentes desde muito cedo na obrade Lacan, já em O Seminário, Livro 3: as psicoses. Desde este tempo o autor afirma existir a possibilidade da compensação primitiva aФ0 pelo que ele denomina "uma série de identificações puramente conformistas" (Lacan, 2008/1955/1956, p. 232). Maleval (2003) remarca que a diferença entre a suplência e a compensação é que esta última faz referências a imagens, servindo como modo de "compensação imaginária ao Édipo ausente" (Lacan, 2008/1955/1956, p. 218). Por outro lado, a ideia de suplência "designa um meio utilizado para manter juntos os elementos da cadeia borromeana" (Maleval, 2003, p. 17 [tradução livre]). Dito de outro modo, na compensação o sujeito lança mão de uma riqueza, via de regra, alucinatória, haja visto estar tomado pela vivacidade do imaginário. Por outro lado, a suplência trata de uma sutileza que acaba por criar um modo particular de amarração dos três registros, um modo particular de inserir-se na linguagem a partir de um elemento também particular. Para este trabalho interessará resgatar o lugar que o corpo pode ocupar como operador desta amarração.

Com um passo adiante dado por Miller quanto à questão da psicose ordinária, Maleval (2003) considera possível pensar a própria inscrição do Nome-do-Pai como uma das possíveis formas de suplência imaginária. Ou seja, a ideia de que um significante toma o lugar do outro paternal, não insuficiente como pode ser observado no caso da fobia de Hans, mas o Nome-do-Pai como sua falta sob o modo da foraclusão: P0 (Askofaré, 2009). A particularidade desta última clínica de Lacan, a clínica dos nós, não se encontra 
exclusivamente no apoio à metáfora paterna, mas sobre as formas possíveis de amarração do nó borromeano. Aqui, a função paterna surge como um quarto termo referido à nominação, cuja função é suplementar os registro Real, Simbólico e Imaginário, articulando-os de maneira borromeana. Assim, o psicótico encontra uma distinta possibilidade de suplência que não se faz pela incidência da castração. A foraclusão do Nome-do-Pai marca a carência da suplência paternaque, contudo, pode ser suprida por outras formas de suplência, "em algum tipo de suplências de segundo grau que implicam uma certa degradação de sua função" (Maleval, 2003, p. 17 [tradução livre]).

Esta degradação de sua função será percebida pela fragilidade do enlaçamento dos três registros do nó. Aqui, a limitação se faz operar sobre o regime de gozo sem, no entanto, equivaler à castração, dada a ausência de um referente fálico. O resultado final do processo é o falo despontencializado de sua condição simbólica e superinvestido no campo imaginário (daí a função de suplência poder ser exercida por ofertas imagéticas como por exemplo na escrita literária, nas modificações corporais, etc). De tal sorte, configuram-se como características principais de uma suplência a invenção singular que realiza função de pacificar o gozo e que ao mesmo tempo mantém o traço da falha a qual ela remedia. Mas afinal, qual será a especificidade da suplência como operadora da função de nó?

\section{O J ovem "gay rico e escravo da beleza"}

Ao longo das entrevistas para o desenvolvimento da pesquisa de doutorado, foi encontrado um sujeito fazendo um uso bastante particular de seu corpo. Trata-se de um jovem homossexual de vinte e sete anos que chamaremos de Léo. A intervenção estética de maior impacto físico e psíquico foi uma cirurgia plástica para o implante de uma prótese peitoral masculina. Além do mais, ele destaca que já gastou bastante dinheiro em cuidados estéticos, cremes hidratantes, tonificantes, estética e plástica dental, além de seguir dietas alimentares rigorosas e uma média de duas horas diárias na academia sete dias por semana. Relata que faz pausas em seu trabalho apenas para refeições e que sua rotina está restrita ao trabalho, às idas à academia e uma relação de "dependência do espelho" (Sic), uma vez que gasta considerável tempo de seu dia se observando, o que é facilitado pela necessidade de seu trabalho como cabelereiro, restando sempre atrás do cliente e voltado para o espelho.

Léo é proprietário de uma rede de salões de beleza onde trabalha de segunda a domingo, de 12 a 16 horas diárias. Este ritmo de trabalho intenso, desde a infância até os dias de hoje, Ihe proporcionou uma 
confortável situação financeira o que the permitiu aos poucos "construir um corpo" (Sic) e passar a se reconhecer. Tal reconhecimento parecia ser impossível no tempo pregresso à cirurgia de implante.

Léo: Eu me sentia que aquele ali não era eu, aquele ali era uma fase, aquele ali ainda não era eu, eu tava em transformação, eu ia mudar muita coisa.

Entrevistador: Como assim?

Léo: Quando eu me olhava no espelho, eu olhava assim, eu não, não sentia que aquele ali era o Léo, entendeu? Eu olhava pro espelho e aquela imagem parecia estranha, eu não me reconhecia, era muito estranho. Eu sentia sempre um estranhamento em relação ao que eu via (Sic).

A família de Léo é de origem financeiramente muito humilde. Seus pais foram garis e ele teve que começar a trabalhar quando ainda era criança recolhendo papelão e latinhas pelas ruas. Queixa-se de que o pai não the deu apoio quando decidiu se tornar cabelereiro. De acordo com Léo, "ele jamais me apoiou em ser cabelereiro pois existe um preconceito comum contra a profissão, né... pois todo cabelereiro é gay" (Sic). Além disso, relata uma completa indiferença de seu pai desde a infância.

Léo construiu um ideal que vetoriza sua estrutura subjetiva, composto por riqueza financeira e um corpo reconhecidamente belo. No começo de sua vida profissional foi auxiliado por outras pessoas em melhor condição financeira e com certo prestígio que trabalhavam em salões de alta classe social. No processo de construção de seu corpo, Léo passa a responder a um Outro socialmente encarnado nos olhares das pessoas dos ambientes por onde ele circula, que sempre o observam em cada detalhe de seu corpo, de seus hábitos e que passam a autorizar imaginariamente uma série de comportamentos de Léo. Assim afirma, "toda vez que você chega em um lugar, qualquer lugar, a pessoa repara em você dos pés a cabeça, repara em você, na sua roupa, repara no seu cabelo, repara na sua pele, repara tudo!" (Sic). O olhar parece dar consistência ao imaginário de seu corpo.

Quanto à sexualidade, Léo se afirma homossexual e que não há qualquer problema em ser aceito como homossexual pelos outros, desde que se tenha bom status social e boa aparência física. Por outro lado, diz que, se ainda hoje tivesse a mesma aparência e condição financeira desfavorável como antes, não seria bem aceito pelos outros, pois "Gay bom é gay rico! Gay pobre não presta! Gay pobre só presta pra ser pessoa espancada na rua ou humilhar. Enfim, se expor ao ridículo, usar drogas, enfim, esse tipo de coisa" (Sic). Léo tem no processo de envelhecimento e nos efeitos da passagem do 
tempo um sério inimigo contra o qual tem que lutar. Ele afirma que evita realizar diversas atividades ao ar livre devido ao risco das marcas do tempo em decorrência dos efeitos do sol sobre sua pele. Durante todo o tempo ele demonstra preocupação obstinada em evitar qualquer situação que pudesse representar uma forma potencial de agressão contra seu corpo, em especial seu rosto, dando especial destaque sobre o medo dos sinais da ação do tempo. Ele considera o rosto como "a coisa mais preciosa que possui" (Sic.) e já tentou fazer aplicações de botox, tendo sido convencido pelo médico a desistir por ter apenas vinte e sete anos.

Para finalizar a apresentação há uma fala que, em paralelo a outras questões levantadas, orientou a hipótese diagnóstica sobre o caso. Para precisar sua problemática ele afirma que "se eu não fosse gay eu não teria nada disso" (Sic). Léo assegura que todas as modificações, aí incluída a prótese peitoral, foram realizadas em decorrência de sua sexualidade. Diz, sem titubear, que sua condição homossexual o conduziu a isto e afirma que pessoas heterossexuais não reparam nos outros, na beleza dos corpos, a forma de se vestir, na expressão do rosto, etc.

Para a compreensão sobre o caso de Léo levanta-se a hipótese de se tratar de uma psicose que se manifesta de forma ordinária, estando a sentença "gay rico escravo da beleza" capturada como um significante que cumpre a função de suplência imaginária. Naturalmente, todos os diagnósticos estão sujeitos à discussão e alteração. Em situação clínica eles possuem um funcionamento experimental, que sempre está sujeito à sua adequação à realidade e eficácia na condução. Após a realização e análise das entrevistas, assume-se que Léo se enquadra na descrição de uma psicose ordinária, a partir de elementos discursivos sujeitos a possíveis alterações. De fato, apenas um processo analítico com maior tempo de duração poderia dar mais consistência à hipótese diagnóstica. Sobremaneira o que interessa aqui é tensionar uma discussão em torno dos possíveis usos do corpo enquanto um dispositivo possível à foraclusão do significante fálico.

\section{O Corpo como Suplência I maginária}

É preciso agora localizar o lugar do corpo como suplência imaginária no processo de organização psíquica de Léo. Ao que a análise pode alcançar, foi possível considerar o modo particular de lidar com o próprio corpo sob a hipótese de uma possível suplência ao Nome-doPai. Chegou-se a tal hipótese a partir da relação aderente que ele estabelece com o olhar do outro, o que parece servir como uma forma de "compensação por identificações conformistas" tal como estabelecido em $\mathrm{O}$ Seminário, livro 3: as psicoses (Lacan, 
2008/1955/1956). Léo afirma que os olhares de suspeita e desaprovação desapareceram após passar por um momento de "evolução pessoal e profissional" (Sic). Esta "evolução" aumentou a partir do momento que realizou a cirurgia para colocar sua prótese peitoral. Após isto, afirma que tudo em torno de seu corpo mudou. Ele ganhou dez quilos, o que fez com que sofresse considerável transformação e passou a fazer outras constantes modificações em sua aparência com tratamentos estéticos menos invasivos. Vale ressaltar que antes da realização da cirurgia ele já havia tentado ganhar algum peso, porém sem êxito. Isso serve como índice que marca a possibilidade de deslocamento do sujeito dentro de determinada ordem discursiva a partir da inscrição de um novo termo na própria carne, em ato.

Durante as entrevistas ele se diz "um escravo da beleza", o que parece funcionar como uma possível suplência a partir da qual um corpo pode advir e assim construir uma nova significação ao Nomedo-Pai faltante. Cumpre notar que Léo pode sustentar a suplência de um modo mascarado por detrás de seu trabalho, uma vez que passa a maior parte do dia de frente ao espelho, invariavelmente com o olhar voltado para sua própria imagem. Assim, acaba por criar uma construção imaginária em que, por trabalhar com a beleza, ser belo torna-se um imperativo.

O psicótico ordinário é aquele que "gostaria muito de dar crédito à efetividade da linguagem, do laço social, da lei de troca, mas não pode devido à carência da metáfora (e seja qual for o modo de suplência), jogar com os semblantes e se implicar subjetivamente" (Gaspard, 2012, p.20 [tradução livre]). Daí o frequente questionamento sobre a autenticidade do delírio nestes casos de psicose. Afinal, seria legítimo considerar a fenomenologia do delírio sob o mesmo estatuto das assim denominadas psicoses verdadeiras? Diante de tal questionamento, Brousse (2009) alerta para o fato de que na psicose ordinária o delírio não se esgota na especulação imaginativa do saber que incide na verdade. Para a autora, na psicose ordinária o sintoma inclui o sentido, porém o faz no senso comum. A impossibilidade de jogar com os semblantes, descrita por Gaspard, encontra seu correspondente no delírio que fixa o real, fixa o sentido e dá consistência a um pseudolaço social. A fixidez do sentido, no caso de Léo, se dá a partir das designações que ele encontra e do caminho que é levado a reafirmar o senso comum.

Complementando tal ideia, Maleval (2003) afirma que as suplências servem como meio de fazer barragem a um gozo invasor. Léo dá testemunho deste gozo invasor quando se refere ao olhar do outro. Aqui, o olhar cumpre uma dupla função: ao mesmo tempo que o invade é o que dá consistência e permite a localização do gozo do Outro. Léo escapa de ser tomado em sua totalidade pelo gozo invasor do Outro ao construir um corpo que serve como armadilha que 
captura o olhar do Outro. A foraclusão do Nome-do-Pai aparece no momento em que este Outro surge sem mediação, sem representação simbólica. A realização da cirurgia faz operar no real da carne algo que não encontra inscrição simbólica, daí a materialidade que torna o significante "escravo da beleza" um determinante de uma série de condutas diárias - em direção ao senso comum - que lhe servem como contenção de gozo. Ainda que se submeter a dietas rigorosas, trocar o sono por mais tempo na academia, rotina extenuante de trabalho sete dias por semana, etc, pareçam práticas mortificantes, elas servem como contenção a este gozo Outro, do olhar invasor.

Há um momento na história de Léo que marca a particularidade da amarração dos três registros como suplência imaginária. Ao relatar sobre o momento pós-operatório, Léo testemunha entreabrir lacunas na própria representação corporal ao se olhar no espelho, tal como segue: "bateu um arrependimento porque eu olhei a cicatriz, eu vi o machucado, e eu senti que eu tinha violado o meu próprio corpo, que eu estava me agredindo, então quando eu olhei no espelho nas primeiras semanas, eu arrependi amargamente do que eu tinha feito" (Sic). A não amarração dos três registros a partir da referência fálica $(-\varphi)$ coloca o sujeito em uma ligação sobretudo imaginária ao Outro e ao eu ideal, construído como suplência. A não extração do objeto a, do deixar cair, pede a criação de um objeto real para dar consistência ao próprio corpo do sujeito.

A relação especular de Léo será mediada pela constante necessidade de se olhar no espelho. Sobre isto, Maleval recorre ao pensamento de Abély (Appud Maleval, 2003) nomeado como "signo do espelho". Ainda que pouco estudado após os anos de 1930, o signo do espelho trata da constante preocupação do sujeito com sua autoimagem que ele examina por longos períodos e de maneira frequente diante de superfícies refletoras. Abély afirma a existência deste signo em diversas psicopatologias, como na melancolia e na, assim denominada anteriormente, "demência precoce", ao que Maleval acrescenta as psicoses ordinárias.

A propósito da sexualidade de Léo, "A forma mais discreta do empuxo à mulher se traduz pela aparição de uma crença homossexual, o que o sujeito concebe como uma atitude passiva e feminina" (Maleval, 2003, p. 28). O empuxo à mulher, no caso de Léo, fica circunscrito no 1 ) desejo pelo implante peitoral que surgiu a partir da identificação a mulheres que fizeram cirurgias de prótese de seios e 2) o sentimento de "poder" (Sic) que ele diz perceber em tais mulheres. A perturbação de ter um corpo masculino ou feminino o coloca diante de um impasse tipicamente edipiano do qual o sujeito psicótico localiza-se somente a partir de uma ex-sistência. A saída psicótica mantém o masculino e o feminino com a não-diferenciação 
entre as posições masculina e feminina. A ligação que ele estabelece entre "poder" (Sic) e a prótese de seio nas mulheres parece ser um índice da possibilidade de fazer (ex)sistir a castração, colocando-a velada sob a imagem dos seios femininos. A homossexualidade com seus traços de identificação a um poder feminino parece servir a esta identificação à sexualidade, como também signo da foraclusão da castração.

\section{Tripla Externalidade em Desordem}

Miller (2009) toma emprestada a ideia de Lacan, que considera poder reconhecer a psicose "por uma desordem provocada na junção mais íntima do sentimento de vida do sujeito" (Lacan, 1998/1957, p. 565), para pensar sobre uma tripla externalidade que se demonstra em desordem, a saber, uma externalidade social, corporal e subjetiva.

Quanto à primeira, a externalidade social, Miller se questiona a respeito de qual seria a identificação do sujeito a uma função social ou profissional. Cabe notar que o autor destaca que parece haver uma "desconexão" do mundo. Ou seja, ele aponta uma falha no laço social nos núcleos constitutivos mais primitivos, como, por exemplo, família e amigos. Quanto a Léo temos um caso particular de suplência. É notável a discrição por meio da qual ele suporta o laço social e da, assim nomeada pelo próprio Miller, identificação social positiva. Ou seja, a partir de uma intensa identificação a uma determinada posição social, geralmente garantida a partir do trabalho (Miller, 2009). Embora sem relatar relacionamentos de maior intimidade, Léo possui boas relações sociais com as pessoas em seu trabalho e, sobretudo, uma favorável situação financeira.

Lacan, no período mais tardio de seu ensino, pensa o Nome-do-Pai a partir de certa pluralidade de possibilidades de amarração dos três registros. Para ele o Nome-do-Pai é uma atribuição de uma função, um "ser nomeado para" (Lacan, Inédito/1974/1975, p. 65). É esta construção imaginária de ser um belo jovem, gay e reconhecido em seu trabalho e riqueza financeira que permite a Léo ascender à condição de ser nomeado para uma determinada posição social. Aqui a construção que ele faz serve como suplência por meio da qual pode, ainda que minimamente, localizar o gozo no campo do Outro através de nomeações realizadas durante o processo de assimilação do seu ideal de beleza e status social. Esta amarração é possível a partir de uma nova narrativa em que o significante "gay, rico e escravo da beleza" (sic) - citação retomada repetidamente ao longo das duas entrevistas - amarra os significantes que lhe permitirão ter um corpo, imaginariamente próprio. Maleval (2003) afirma que a pluralização do Nome-do-Pai dilata as perspectivas sobre a pluralidade de resoluções possíveis para dar conta da função paterna. 
A propósito da segunda externalidade, a corporal, Miller (2009) propõe o corpo como o Outro do sujeito. O autor toma a afirmação de Lacan (1936) segundo a qual o sujeito não é um corpo, mas ele o possui, para então compreender os artifícios necessários à construção de uma imagem corporal. Léo faz o que Gaspard (2012) nomeia por práticas compensatórias, a partir de seu "processo de evolução" (Sic) do qual a prótese peitoral, por exemplo, passa a funcionar como um "acessório a mais" (Sic), usado perante o risco de ser tomado pelo Outro totalitário em decorrência de P0. Este "acessório" dá contorno a um corpo anteriormente sentido como estrangeiro. Cabe lembrar que, quando mais jovem, Léo tinha dificuldade em se reconhecer ao se olhar no espelho. Ao tomar o texto $O$ estádio do espelho como formador da função do eu (Lacan, 2006/1936), localiza-se uma problemática correlata à passagem do primeiro tempo, imaginário, para o segundo tempo, simbólico, o que Léo tenta fazer operar a partir das intervenções em seu próprio corpo.

Léo, diante da perplexidade e hesitação frente ao espelho, aponta algumas falências no processo de identificação imaginária ao outro. Este, por vezes encarnado na figura do próprio pai, aparece de maneira frágil, um tanto quanto débil e que reaparece nos momentos em que prefere negar a presença de Léo no mundo por sua condição homossexual. A ausência da possibilidade de identificação, ainda que "tomado no equívoco da identificação espacial" (Lacan, 2006/1936, p. 97) indica a não assunção da imagem de um corpo próprio, circunscrito ao Nome-do-Pai. A construção da suplência imaginária em torno do sintagma gay, rico e escravo da beleza inscreve-se como um substituto ao Ideal no lugar da transmissão possível a partir do Nome-do-Pai, produzindo-se um substituto para o lugar da lei, tal como será visto mais a frente a partir do Esquema I.

Vale ressaltar que a construção sobre a qual Léo se estrutura é vacilante. Como suplência do significante do Nome-do-Pai, o significante que vem substituir a inscrição fálica mostra certo afrouxamento do nó que mantém os três registros quando o sujeito olha o efeito radical sobre seu corpo após a realização da cirurgia de implante peitoral. Ao falar sobre como foi o momento pós-operatório, Léo relata sobre "aquele corpo, ainda magro, mas com uma prótese masculina, ai eu olhei e falei: 'olha o que eu fiz comigo, eu não precisava ter feito isso'" (Sic). Este reencontro é o momento em que a sustentação via suplência imaginária derrapa. Aí, o significante que faz suplência ao Ideal acaba por conduzi-lo a um estado melancólico, uma vez que "a invenção singular que opera uma pacificação do gozo conserva um traço da falha a qual ela remedia" (Maleval, 2003, p. 18).

Para concluir a análise do caso em torno da problemática da tripla externalidade em desordem, tal como cunhada por Miller, existe ainda a externalidade subjetiva. A vacuidade, o vazio, é um dos 
principais índices diagnósticos para a psicose ordinária, podendo ter nos fenômenos de corpo (Stevens, 2009) certa compensação. Para preencher esta vacuidade, o sujeito colocará a dimensão dialética do Outro de lado, como objeto de descarte. Em outras palavras, perdese a dimensão do erro e privilegia a certeza de seu pensamento, mesmo que sofra as consequências mais funestas. No caso de Léo, esta dimensão fica evidente quando ele reconhece seu sofrimento sob o significante "escravo da beleza" (Sic) e ainda assim continua com seu "processo de evolução" (Sic) corporal, mesmo com todas as privações e sacrifícios necessários para atingir seu objetivo.

Assim a análise do relato de Léo, no rastro da pena de Miller, permite considerar que ele faz uma construção bastante ímpar sobre a qual procura aglutinar e relacionar alguns significantes que possam darIhe sustentação, a partir dos quais possa se apropriar de alguma narrativa. Dito de outro modo, os significantes que ele encontra lhe permitem se distinguir em uma externalidade socialmente reconhecida (pois pode ser financeiramente distinguido em seu trabalho como cabelereiro); uma externalidade corporal (a juventude e a beleza que estampam seu corpo); e por fim uma externalidade subjetiva (a homossexualidade e a riqueza como possibilidades de estar circunscrito numa aparência de laço social).

Aqui, evidencia-se certa reverberação no caso de psicose de maior reconhecimento dentro da teoria psicanalítica: Daniel Paul Schreber. Sem alongar nos meandros do texto freudiano, é possível extrair certas elucubrações quanto à função que o corpo parece servir à Léo, cumprindo função análoga à "mulher de Deus" em Schreber. Como significante Ideal, substitui o Nome-do-Pai tendo como efeito a produção de um substituto para o lugar da lei. Lancemos mão do Esquema I (Figura 1), apresentado em De uma questão preliminar a todo o tratamento possível da psicose, de 1957.

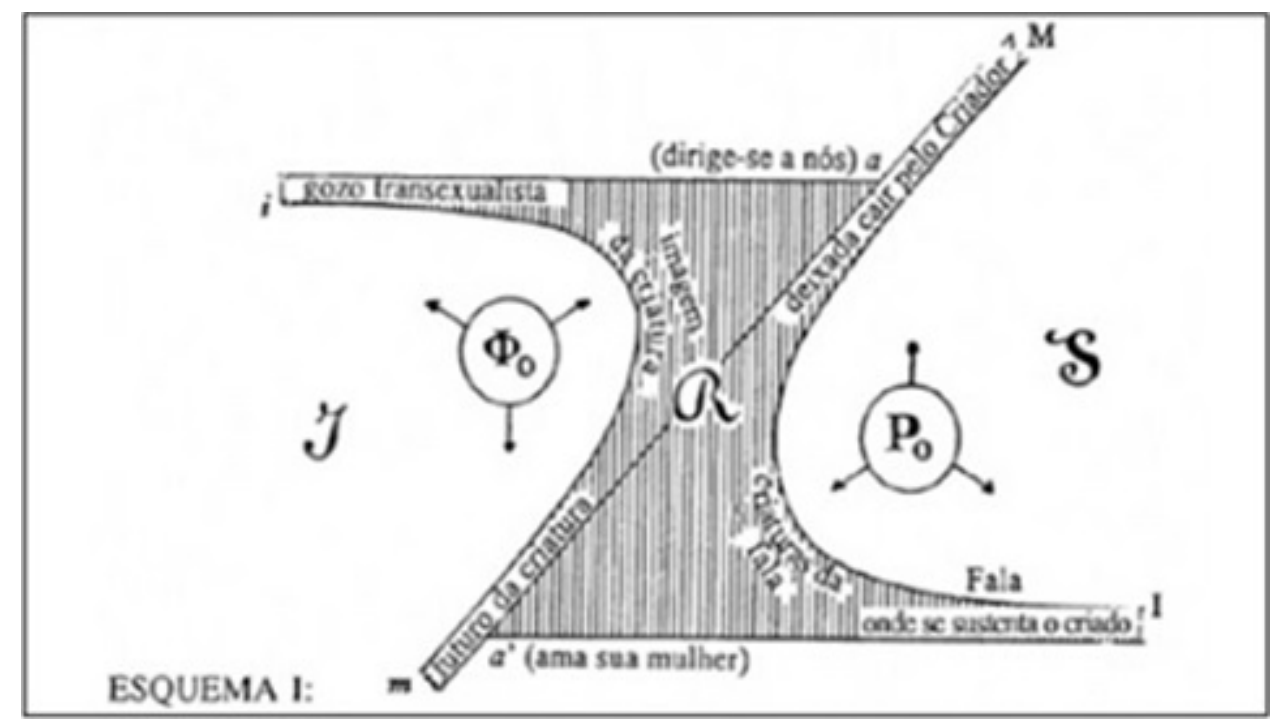

Figura 1. Esquema I (Lacan, 1957) 
Lacan apresenta a tese de que a foraclusão do Nome-do-Pai (P0) e o efeito sobre a zerificação da função fálica (Ф0) traz dois esburacamentos: no imaginário (im $\Phi$ ) e no simbólico (MIP). Quanto ao imaginário no caso de Léo, observa-se certa deformação relativa ao estranhamento diante do espelho e o não reconhecimento de seu próprio corpo no momento anterior à cirurgia de implante peitoral. Assim, a linha imaginária (i-m) não apresenta um ponto de ancoragem fálico que possibilite a alienação de Léo a uma imagem de seu corpo.

Com o estreitamento da realidade, Léo tem sua vida organizada a partir de um novo significante que serve à demarcação de um novo ordenamento da bateria de significantes que daí possam surgir. Gay, rico e escravo da beleza lhe cria a possibilidade de encontrar-se em determinada posição subjetiva a partir do ancoramento do significante na produção de sentidos que ele encontra no movimento de construção do corpo. O significante encontrado serve ainda para Ihe permitir um posicionamento perante a divisão sexual. Ainda que ex-sistente na psicose, a condição homossexual lhe permite ser tomado pelo desejo do Outro a partir do lado feminino. Por sua própria característica de dubiedade, o significante permite a localização de Léo a partir da construção de um belo corpo masculino, com características que reafirmam os componentes próprios do modelo corporal masculino - como no caso da ostentação de um peitoral proeminente, poderoso, forte - ainda que por meio de sua identificação ao sexo feminino.

A proporção que fica resguardada entre os quatro termos do Esquema I ( $\mathrm{i}, \mathrm{m}, \mathrm{M}, \mathrm{I})$ permite a organização do lado da realidade, mesmo não havendo a extração de um objeto de gozo que possa fazer enquadre à realidade (Jacinto \& Costa, 2011). A função de suplência serve para indicar este algo a mais que é extraído da própria condição do significante não se prestar a uma significação prévia, mas que no caso da psicose surge como processo de obturação de uma possível falta. O efeito será a não extração de um objeto, o que remete Léo à sua condição "escravizada" a este olhar que o persegue, mas que ao mesmo tempo o sustenta, o localiza diante o desejo do Outro. O Outro, ao ter seu objeto de gozo circunscrito a partir do Ideal do corpo de Léo, torna-se menos terrificante, ainda que não dialetizável.

Uma questão capital que convém destacar é a relação de Léo com o saber. A aquisição de uma representação imaginária do corpo - ainda que tangenciando um pseudo-simbolismo - abre a possibilidade dele ordenar uma relação ao saber que não será possível senão pela existência de um certo intervalo entre S1 e S2. Gaspard, Silva Junior, Dunker, Assadi e Doucet (2010) afirmam que para existir a crença a 
um saber é preciso qualquer coisa que possa faltar na cadeia significante. A produção de um discurso que possa totalizar um determinado saber somente é possível por um momento prévio de reconhecimento de uma falta de saber. A crença é a representação da possibilidade de adquirir um saber que faça ligação entre os significantes S1-S2-...Sn. É para responder à falta ao ser do Outro que a constituição de um saber será possível. De outro lado, para o sujeito psicótico não há um enigma constitutivo ao qual é preciso responder. "A descrença coloca em função [...] se afasta ela também da propensão particular que alguns sujeitos psicóticos têm a se confundir com uma hipernormalidade, a 'se holofrasear' aos enunciados do discurso corrente" (Gaspard et al., 2010, p. 20 [tradução livre]). O outro está sempre lá, o que a figura da holófrase destaca pela ausência de um intervalo entre S1 e S2. Para o psicótico trata-se de um desacordo com o enigma que impedirá o sujeito construir um saber sobre a representação do próprio corpo.

Léo parece "vestir-se" de um corpo que cumpre uma função de armadilha ao olhar do Outro a fim de dar-Ihe materialidade. Assim, a possibilidade de construção de um saber sobre si torna-se turvada. A suplência aparece nos momentos em que ele considera possível viver somente colado a um Ideal. Em outros termos, ele parece não apresentar condição de construir um saber sobre 0 ser. A impossibilidade de jogar om os semblantes, tal como afirma Gaspard et al. (2010), não o permite o benefício da dúvida e, assim, construir um saber (ainda que claudicado) sobre seu ser. No caso de Léo não há construção de um saber, o que o conduz à conclusão de poder existir sob o signo de um gay, rico e belo. Léo encontra-se impedido de incorporar a representação de seu próprio corpo. De acordo com Askofaré (2010), a incorporação é uma operação a partir da qual o corpo do falasser pode ganhar consistência ao fazer passar no organismo o simbólico, tendo como efeito a produção de um corpo.

Como consequência, uma vez tendo sido incorporado, o corpo do simbólico torna-se incorporal, assim o simbólico mantém o corpo, atestando que o simbólico é o corpo - agrupamento e articulação (Askofaré, 2010, p. 62).

É como se o corpo não o pertencesse, uma vez que Léo não alcança esta representação incorporal de seu corpo. A necessidade da materialidade de um corpo belo, que precisa ser constantemente vigiado para ganhar consistência, mostra o impedimento do reconhecimento do corpo simbólico. Numa espécie de deslocamento de um significante que possa representar seu corpo, este é substituído pela materialidade real. Trata-se da "substituição de um elemento real, r, pelo significante; ou seja: r/S" (Askofaré, 2010, p. 112), operação análoga à substituição do Nome-do-Pai pelo I deal. 
A partir da noção de suplência na teoria psicanalítica abre-se um novo campo problemático: a questão da identificação ao objeto e suas consequências clínicas. Se a suplência abre um novo campo de possibilidades de enodamento entre os três registros, as identificações maciças fazem retornar um antigo problema: a circulação pulsional. É de enorme valia resgatar o pensamento de Freud que, ao tratar dos processos de identificação e de sublimação, em especial a partir de 1920, coloca a problemática relativa à circulação pulsional em primeiro plano. Preocupado com a transformações das pulsões no momento em que ocorre o processo de sublimação, Freud (1923) percebe com fineza a passagem da libido sexual em narcísica, restando uma certa lacuna em seu pensamento sobre o que ocorreria no momento subsequente. "Teremos de averiguar se esta transformação não pode ter como consequência outros destinos pulsionais; se, por exemplo, ela não pode ocasionar uma desfusão das diversas pulsões que se acham fundidas entre si" (Freud, 1980/1923, p. 48).

De tal sorte, ao considerarmos os maciços investimentos identificatórios de Léo a padrões de beleza furtivamente ofertados na sociedade contemporânea - criando um determinado comportamento de consumo - poderia haver a substituição da satisfação objetal por satisfação narcísica.

A satisfação pulsional se daria no interior do indivíduo, causando desfusão das pulsões - lembremos que a identicação, implicada no consumo de uma determinada imagem, é um fenômeno para o qual é imprescindível a dessexualização. Não podemos esquecer que a identificação também pode ser uma das causas da desfusão (Metzger \& Silva Junior, 2010, p. 571).

Portanto, há que se alargar a investigação de tal temática sobre os destinos pulsionais atrelados aos processos de identificação e ao que se pode produzir a partir de tais investimentos na sociedade contemporânea. Afinal, estaria, como no caso da psicose ordinária, o sujeito resguardado por detrás das identificações ordinárias, mesmo tratando-se de investimentos que levam à desfusão pulsional e a um sobre investimento na imagem?

\section{Referências}

Askofaré, S. (2009). Da subjetividade contemporânea. A peste, 1(1), 165-175. doi: 10.5546/ peste.v1i1.2705 
Avdelidi, D. (2016). La psychose ordinaire: la forclusion du Nom-duPère dans le dernier enseirnement de Lacan. Rennes, França: PUR.

Brousse, M.-H. (2009). La psychose ordinaire à la lumière de la théorie lacanienne du discours. Quarto - Retour sur la psychose ordinaire, (94/95), 1-13.

Freud, S. (1980). O ego e o id. In Edição standard brasileira das obras psicológicas completas de Sigmund Freud (Vol. 19, pp. 13-83). Rio de Janeiro: Imago. (Originalmente publicado em 1923)

Gaspard, J. L., Silva Junior, N. S., Dunker, C. I. L., Assadi, T. C., \& Doucet, C. (2010). Psicanálise e análise do discurso: elementos para uma investigação clínica futura. A peste, 2(2), 361-378.

Gaspard, J. L. (2012). Nouveaux symptoms et lien social contemporain. In J odeau-Bell \& L. Ottavi, Les fondamentaux de La psychanalyse lacanienne: répères épistémologiques, conceptuels et cliniques (pp. 357-372). Rennes, France: PUR.

Jacinto, R. R., \& Costa, A. M. M. (2011). Considerações sobre o conceito de estabilização nas psicoses. Arquivos brasileiros de psicologia, 63(2), 49-57.

Lacan, J. (2006). Le stade du miroir comme formateur de la fonction du Je telle qu'elle nous est révélée dans l'expérience psychanalytique. In: Écrits. Paris: Seuil. (Originalmente publicado em 1936)

Lacan, J. (2008). Le Séminaire, livre 3: psychoses. Paris: Le Seuil. (Originalmente publicado em 1955/1956)

Lacan, J. (1998). De uma questão preliminar a todo tratamento possível da psicose. In Escritos (pp. 537-590). Rio de Janeiro: Zahar. (Originalmente publicado em 1957)

Lacan, J. (1998). A significação do falo. In Escritos (pp. 692-703). Rio de Janeiro: Zahar. (Originalmente publicado em 1958)

Lacan, J. (1998). Subversão do sujeito e dialética do desejo no inconsciente freudiano. In Escritos (pp. 807-842). Rio de Janeiro: Zahar. (Originalmente publicado em 1960)

Lacan, J. (Inédito). O seminário, livro 21: RSI. (Originalmente publicado em 1974-1975).

Maleval, J-C. (2003). Eléments pour une appréhension clinique de la psychose ordinaire. Séminaire de la découverte freudienne 18 et 19 janvier. Cours à l'Université de Rennes 2, Rennes, France.

Metzger, C., \& Silva Junior, N. (2010). Sublimação e pulsão de morte: a desfusão pulsional. Psicologia USP, 21(3), 567-583.

Miller, J. A. (1998). La psychose ordinaire, La convention d'Antibes. Paris: Agalma Seuil.

Miller, J. A. (2009). Effet retour sur la psychose ordinaire. In Quarto 94-95: Retour sur la psychose ordinaire (pp. 40-51). Bruxelas: École de la Cause freudienne. 
Stevens, A. (2009). Mono-symptômes et traits de psychose ordinaire. In: Quarto 94-95: Retour sur la psychose ordinaire (pp. 7395). Bruxelas: École de la Cause freudienne.

Tironi, A. C. (2010). A psicose ordinária e os inclassificáveis das categorias lacanianas. Opção Lacaniana online, 1(1), 1-11. Recuperado

de http://opcaolacaniana.com.br/pdf/numero_1/Psicose_ordinaria. pdf

Zebrun, M. (2010). A clínica diferencial das psicoses e as psicoses ordinárias. Opção Lacaninana online, 1(3), 1-9. Recuperado de http://www.opcaolacaniana.com.br/pdf/numero_3/A_clinica_dif erencial_das_psicoses_psicose_ordinaria.pdf

\section{Endereço para correspondência}

\section{Tiago Humberto Rodrigues Rocha}

Universidade Federal do Triângulo Mineiro

Rua Bahia, 870, apto 701-B, Santa Maria, CEP 38050-130, Uberaba - MG, Brasil

Endereço eletrônico: tiago.rocha@uftm.edu.br

Recebido em: 25/10/2018

Reformulado em: 22/03/2019

Aceito em: 22/03/2019

\section{Notas}

* Psicólogo, Psicanalista, Doutor com dupla titulação em Psicologia Social pela USPSP e pela Université de Rennes 2 (França), professor Adjunto do Departamento de Psicologia da Universidade Federal do Triângulo Mineiro.

Financiamento: Capes.

Este artigo de revista Estudos e Pesquisas em Psicologia é licenciado sob uma Licença Creative Commons Atribuição-Não Comercial 3.0 Não Adaptada. 